\title{
Impact on The Supply Chain in a Hospital Environment Caused by the Coronavirus Inside the State of Amazonas
}

\author{
Mayko Pinheiro da Silva, Gabriela de Mattos Veroneze, Marcelo Albuquerque de Oliveira, \\ and Ingrid Marina Pinto Pereira
}

\begin{abstract}
With the emergence of a pandemic in the world caused by the new coronavirus (COVID-19), many companies closed doors because of the lack of capital to maintain operational performance. Still, others reinvented and adapted themselves during this problem. The impact was no different on the industries, mainly on their supply chain, on inventories, and production rates, whether they are small, medium, or large. The fact is that no one left unscathed as a result of this pandemic. The general objective of this study was to present the impact on the supply chain in the hospital environment in the interior of the Amazonas state, which has an entirely different logistics arrangement from anywhere in the world. The results indicate that the proper functioning of the hospital system is directly related to the capacity to supply adequate materials that guarantee the execution of procedures with quality and higher patient satisfaction.
\end{abstract}

Index Terms - Supply-Chain, Amazon, COVID-19, Hospital supplies.

\section{INTRODUCTION}

With the emergence of the pandemic in the world, many affected companies had to shut their doors. Due to this scenario, many products are no longer in demand, and thus supplies and finished products are stored in the company itself. In contrast, other products have their market grow; this is the case with medical and hospital materials, such as personal protective equipment, testing kit and medication. Suppliers have difficulties in serving their customers, as the pandemic has led to the demand for materials in large quantities, as a result many hospitals and emergency rooms suffer from the absence of these materials, not to mention that the prices of essential products have been substantially higher, in addition there is a scarcity of products and suppliers in the Brazilian Market and even internationally due to the higher demand.

In the northern region, in the interior state of Amazonas (literally in the middle of the Amazon jungle), in addition to the difficulties identified previously, another factor that presents itself is "logistics", since the municipalities are separated by rivers, goods transportation can take up to three to four days to arrive from the capital. Thus, the transportation of goods in the Amazon occurs mostly by river, due to the absence of other viable modes of transport

Published on September 11, 2020.

Mayko Pinheiro da Silva, Federal University of Amazonas, Brazil.

Gabriela de Mattos Veroneze, Federal University of Amazonas, Brazil. (corresponding e-mail: gveroneze@ ufam.edu.br)

Marcelo Albuquerque de Oliveira, Federal University of Amazonas, Brazil. Ingrid Marina Pinto Pereira, Federal University of Amazonas, Brazil. in the region, these difficulties make transportation, and consequently products' prices higher than for any other region in Brazil.

In general, this research seeks to answer the following problem: How can the impact on the supply chain in the hospital environment caused by the coronavirus in the interior state of Amazonas be controlled, or at least lessened?

Based on this problem, this research has the general objective of presenting the impact on the supply chain in a hospital environment caused by the coronavirus pandemic considering the information reassessment process. In order to achieve the general objective, it was necessary to divide this study into the following specific objectives: to evaluate the supply chain process in the hospital environment in the interior of the state of Amazonas, reassess the process of information, acquisition, receipt and storage of material; elaboration of a new planning; and to propose an effective control method for the supply chain.

The remaining of the article is organized as follows: section II presents the background information, section III describes the methodological procedures, section IV shows the results of the research and section and section $\mathrm{V}$ shows the conclusion.

\section{LITERATURE REVIEW}

\section{A. Logistics}

According to [1], [2]. Logistics is considered a set of routine activities applied within an organization, in a process of transforming raw materials into finished products, planning and control, this operation is present in the supply chaim, being responsible for maintaining relationships between suppliers, manufacture, product distribution and customer.

Logistics is defined as a process for planning, implementing and controlling the flow of materials effectively and efficiently in terms of time, quality and costs of raw materials, stock in process, finished product and services, covering from the origin until the point of consumption in order to meet consumers' requirements [1], [3], [4].

According to [5], the mission of logistics is to have an efficient supply chain, where the process must flow smoothly and perfectly so that all process planning does not suffer damage in its normal flow.

In [6], its highlighted that supply chain management if one of the essential tools for a company's strategy. However, the implementation of this methodology is a high level of complexity as it encompasses all material flow. 
Such management seeks to synchronize and converge the strategic and operational competencies of the external and internal agents of the chain.

A point worth of highlighting in management is the standardization of processes, one of the greatest allies for proper supply chain logistics management.

Therefore, knowing and understanding supply chain management is essential to identify the organization's need and to be able to optimize all processes, contributing to excellence in the integration between the stages of a supply chain, such as transport, inventory and cost, thus obtaining a competitive advantage by encouraging innovation and reducing expenses at different stages of production.

\section{B. Logistics and Materials transportation}

Transport is one of the main logistical functions, as it is responsible for moving the product from one location to another, starting at the beginning of the supply chain. As a result, it is possible to ensure that customer demand is met as specified. The objective of transport and logistics goes beyond moving materials. They are now a management tool that can reduce costs and improve customer satisfaction [7].

Currently, logistics management allows the integration of all sectors that act mutually directly to serve the customer, such as materials management, supplies, sales, production control, receiving and delivery, the latter two being directly linked to transportation [8].

\section{Supply of Hospital supplies in the interior of the State of Amazonas}

Considering the importance of medicines to fight diseases and, consequently, to rescue health, it is possible to affirm that the preservation of their quality must be guaranteed form their manufacture to the dispensing of medicines to the patient. In this way, storage, distribution and transport conditions play a fundamental role in maintaining the quality standards of drugs. In this context, the pharmaceutical assistance logistic cycle (acquisition, programming, storage, distribution and dispensing) must have the necessary quality and rationality, in the appropriate quantities [9].

The literature on services offered to the population presents a significand importance attributed to logistics as a fundamental element for the efficient and effective management of the materials' supply. This type of management is, in general, understood as the management of related flows of products, information and financial resources, ranging from the initial supply process to the final consumer[3], [10]-[12].

In this context, the main objective of logistics it to minimize the cost of the operation for a given level of service, being and important process in making it possible to achieve the flow of material supply in space and time, which seeks to reach a desired level [13].

The state of Amazonas is one of the largest territorial states in Brazil, with a specific logistics to access the interior. The products usually come by airplane or shipment to the capital and are transported by small boats to the rest of the cities. It can take up to two days for a boat leaving Manaus (the capital) to arrive in its destination, since it has to navigate smaller rivers and between the forest [14].

\section{Corona virus pandemic and the impact on the supply chain}

Epidemic outbreaks are a special case of supply chain risk (SC), characteristic of long-term interruption, cascade effect and high uncertainty. This outbreak poses risks for the supply chain, which is distinctly characterized by three components. These components are:

(i) existence of long-term interruption and its unpredictability;

(ii) simultaneous propagation of disruptions in the $\mathrm{SC}$;

(iii) simultaneous interruption in supply, demand and logistics infrastructure [15].

Unlike others, the risks of interruption, epidemic outbreaks start out small, but rapidly increase and spread across many geographical regions. The recent coronavirus outbreak (COVID-19/ SARS-COV-2) came from the Wuhan area in China, and immediately impacted exports and drastically reduced the availability of supplies in global supply chains [16].

In such a turbulent environment. Companies facing epidemic outbreaks have a series of common questions to ask, such as, how long can the chain sustain a disruption, how long does it take for a SC to recover after an epidemic outbreak, what policy SC operational (eg, accepting time penalties; using prepared contingency pandemic plans; reacting situationally, changing policy operations during the period of the epidemic) is the most efficient way to deal with disturbances at different levels of the epidemic's severity [17].

According to [15], the pandemic affected the main economies, including the G7 countries, which jointly share $60 \%$ of the world supply and demand (GDP), $65 \%$ of world manufacture and $41 \%$ of world's manufacturing exports; therefore, as these economies are now severely affected, the rest of the world will follow suit.

In [18] a macroeconomic model and shows that the spread of COVID-19 in an outbreak can cause a demand-driven decline, give rise to a cycle of destruction of supply demand and open the door to spirit-induced stagnation traps pessimistic animals. Assuming that the supply interruption will be severe and persistent, [18] theoretically illustrate that the pandemic may induce a recession driven by demand for its negative impact on the agents of future productivity growth.

\section{E. Absence of medical supply in a hospital environment in the interior of the state of Amazonas}

The shortage of prescription drugs has impacted clinical patients and created safety challenges for many years, affecting some of the basic medical products. Historically, most of the drug shortages have affected generic injectable products attributable to manufacturing facility quality problems and a lack of redundancy in the supply chain.

In 2014, FDA experts noted that "to truly eradicate or minimize the occurrence of interruptions in the supply and/or shortages of drugs, manufacturers must not only comply with good practices, but must also invest in modernization and keep excellent manufacturing quality.

Unfortunately, successful long-term solutions still need to be implemented.

According to [19], in the state of Amazonas due to 
abnormalities of the pre-announced natural phenomena, supply problems affect the survival of the local population, especially in the interior communities. Therefore, logistical strategies can be implemented to alleviate the needs of the Amazonians in the occurrence of these events.

\section{Methodology}

This research was characterized as descriptive, explanatory and applied, as it aims to clarify and present the importance of controlling the impact on the supply chain in a hospital environment caused by the Coronavirus pandemic in the interior of the state of Amazonas, as well as describing the facts and phenomena in what happened in the procedures in the supply chain, with the need to solve a certain problem in practice.

As for the means, the research is characterized as bibliographic and documentary. In the view of [20], bibliographic research is developed based on material already prepared by other researchers, consisting mainly of books and scientific articles, being the basis for supporting the theme in the view of theorists.

Documentary research, on the other hand, aimed at analyzing relevant documents, such as laws, internal regulations, reports, procedure manuals, among others. The characterization of the research was predominantly qualitative, which according to [21] does not use numbers to analyze its variables.

For the literature review, online searches were carried out from key words, such as, supply chain control, material transport logistics, transport logistics in difficult areas, supply chain network, Coronavirus medical equipment supply chain impact, absence of medial and hospital supplies in the interior of the state of Amazonas.

\section{PROPOSAL FOR AN EFFECTIVE CONTROL METHOD FOR THE SUPPLY CHAIN IN THE HOSPITAL ENVIRONMENT}

The concept of supply chain management is related to the management of the supplies, which can be defines as a set of three of more entities (organizations or individuals)directly involved in the flows of products, services, finance and information from a source to a customer and vice versa [22].

In order for a supply chain management be successful, leadership support and understanding of the importance of its management it is necessary, to benchmark from successful business, share knowledge and common understanding between all members and institutionalization of continuous improvement initiatives.

The concept of supply chain management has grown since the 1980s, when the concept emerged and companies began to understand the benefits of collaborative relationships within an outside their own organization [23], [24]. However, despite the fact that, in recent decades, the scope of supply chain management has increased considerably, there are still limitations in its approach to the healthcare value chain [25].

Health organizations are institutions in which the client (that is, patient), when seeking the service, is part of the entire process until its end. In this sense, the management of the health supply chain must integrate the sequences of actions defined for the generation of products and services, considering that each procedure requires a specific combination that varies between different organizations, types of patients and heath professionals [26]. There is a consensus in academia that heath care supply chains are more complex that other sectors, surrounded by issues and the pressure to deliver faster equipment and medicine since the penalties for not doing so are very high [27].

Complexities and politically oriented elements are expected, challenges to the direct applications of supply chain management techniques and concepts [28]. For example, heath organizations often face a diverse set of stakeholders with varying and confliction interests. This combination of standardized and contingent services makes hospitals "relatively inefficient" due to the cost of equipping and operating this multi-activity supply chain.

Due to this complexity, one of the main characteristics of the health care supply chain is its division into two approaches: internal and external. The external one includes processes related to suppliers, such as negotiation and purchase, tenders (in the case of public health organizations), technical assistance and maintenance, supply logistics, etc. The internal supply chain comprises process management within hospital boundaries that will support the flow of material, information and patients between departments, units or sectors within the hospital [29].

In the manufacturing industry, [30] identified 27 lean practices most commonly implemented in supply chains. However, when considering health organizations, these lean practices can undergo significant adaptations [31]. In addition [32] indicated that the number of lean practices implemented in the health care supply chain is likely to be much lower. In fact, they suggest that the lack of homogeneity related to the implementation of lean practices in the health care supply chain deserves careful considerations by health organizations.

Simulation-based techniques can be used to develop or evaluate complex systems [33], allowing a better understanding of the processes and supporting managers in the decision-making processes [34]. Simulation models can be used as tools to analyze the response of a system in different scenarios without necessarily disturbing it [35].

Data mining can also be used to simulate supply chain network different scenarios [36]. In [37] the authors show how it is possible to have an effective supply chain if an inventory control model is applied.

In general the use of simulation modeling to analyze the supply chain has some advantages, such as: the possibility of dealing with situations of high variability; generally lower investments compared to changes implemented directly in real systems; possibility to control the conditions under which the simulations are carried out; and visualizing supply chain behavior. In turn, some disadvantages are also noteworthy, such as: requiring a significant amount of data; great experience and knowledge about software used; considerable time demand to adequately represent the intended model [38], [39].

The authors in [40] proposes a first solution the Kanban implementation system with a priority management policy, as an effective management system for hospital supplies and inventory. The second proposition is a flexible implementation structure to reduce and master the stochastic 
effect from suppliers. Finally, the colorful and timed Petri net is used to model logistical flows of drugs with the above two propositions and will serve as control and decision support, a tool for the drug supply chain.

In [41] a proposal for a collaborative management of inventory in hospital supply chains showed that the collaboration between hospital and distributor works. [42] shows a literature review on hospital supply chain network that shows how important is a multicriteria approach.

\section{RESULTS AND DISCUSSION}

Regarding the failures that occur in the distribution logistics services in the interior cities of the Amazonas state, even if companies follow their business agreement, the transportation structure is still very hard to be modelled since the service is provided by boat thru river. These are factors that hinder the progress of business activities, during the transportation of goods, with a high number of good losses being reported, a factor that elevate expenses of companies that need logistical services in the municipality. The lack of proper temperature control inside the boats is one of the causes of goods loss.

The results of this research point to many flaws in the supply and distribution chain the state in Amazonas, in general. However, still few studies have been developed addressing this topic, and that can provide results that can assist decision making by governments and distribution companies in different areas of logistics in that region.

The lack of public assistance the owners of the companies created their own alternative to circumvent the obstacles that occur during the process of locomotion and cargo receiving, some created their own ports or acquired their own ferry to improve the quality products and services. Others look for boats and there are still those that look for those that offer a lower cost.

Investments aimed at improving transport infrastructure conditions in the region will considerably reduce the logistical costs of this performance component, which, notably, they represent most of the total logistical cost of the production chains. Enabling multimodality and intermodally of transport in the Amazon region represents the exploitation of the water potential. Partnerships with nongovernmental organizations, technological support from the government and the undertakings involved in the context to enable the existence of facilities destined to the processing and shipping bulk materials that arrive to the capital of the state faster and then separating for the smaller municipalities.

\section{CONCLUSION}

The SARS-Cov-2 pandemic has overwhelmed heath systems, leaving many centers without essential equipment to prevent the spread of the virus or to treat patients with COVID-19. Most of the missing products were consumable, such as connectors for invasive and non-invasive mechanical ventilation and personal protection equipment (PPE).

The companies that generally supply these products were unable to meet high demand during the pandemic; many items were out of stock and inaccessible through the usual channels.

The lack of equipment limited therapeutic options for many patients and contributes to the spread of infection and the collapse of the system by failing to protect professional health services.

In essence, through this research, the supply chain management is a very useful resource when the objective is to produce and provide quality health services at reasonable costs. The adoption of this practice originally developed in an industrial environment, however, is often difficult.

The proper functioning of the hospital system is directly related to the ability to adequately supply materials and supplies that guarantee productivity, execution of procedures with quality and patient satisfaction.

It is noticed, however, that improving internal efficiency is not enough for theses organizations to remain competitive, being necessary to manage external factors that influence the organization.

\section{ACKNOWLEDGMENT}

The authors thank the Postgraduate Program in Production Engineering (PPGEP) of the Federal University of Amazonas (UFAM) for their support and structure. This work was carried out with the support of the Amazonas State Research Support Foundation (FAPEAM) under PosGrad Program.

\section{REFERENCES}

[1] Ballou, R.H., Business logistics/supply chain management: planning, organizing, and controlling the supply chain. 2007: Pearson Education India.

[2] Moraes, J.M., Análise do mapeamento do fluxo de informações e de materiais na cadeia de suprimentos das indústrias automobilísticas. 2010.

[3] Mentzer, J.T., T.P. Stank, and T.L. Esper, Supply chain management and its relationship to logistics, marketing, production, and operations management. Journal of business logistics, 2008. 29(1): p. 31-46.

[4] Platt, A.A. and R.d.S. NUNES, Logística e cadeia de suprimentos. Florianópolis: Departamento de Ciências da Administração/UFSC, 2007: p. 1-88

[5] Van Wassenhove, L.N., Humanitarian aid logistics: supply chain management in high gear. Journal of the Operational research Society, 2006. 57(5): p. 475-489.

[6] Gomes, C.F.S. and P.C.C. Ribeiro, Gestão da cadeia de suprimentos integrada à tecnologia da informação. 2020: Editora Senac Rio.

[7] Gibson, B.J., J.T. Mentzer, and R.L. Cook, Supply chain management: the pursuit of a consensus definition. Journal of business logistics, 2005. 26(2): p. 17-25.

[8] RODRIGUES, K.C. and M.H.S. RABELO, A importância do transporte na logística empresarial. Revista Acadêmica Conecta FASF, 2017. 2(1).

[9] Bowersox, D.J., D.J. Closs, and T.P. Stank, 21st century logistics: making supply chain integration a reality. 1999.

[10] Christopher, M., Logistics \& supply chain management. 2016: Pearson UK

[11] Cavinato, J.L., Supply chain logistics risks. International journal of physical distribution \& logistics management, 2004.

[12] Lai, K.-h., E. Ngai, and T. Cheng, Measures for evaluating supply chain performance in transport logistics. Transportation Research Part E: Logistics and Transportation Review, 2002. 38(6): p. 439-456.

[13] Holguín-Veras, J., et al., On the appropriate objective function for post-disaster humanitarian logistics models. Journal of Operations Management, 2013. 31(5): p. 262-280.

[14] Bonifaz, J.L., F. González-Vigil, and R. Urrunaga, Logistics and markets: Overcoming the challenges of a difficult geography. The Latin American Competitiveness Report, 2001. 2002: p. 44-61.

[15] Ivanov, D., Predicting the impacts of epidemic outbreaks on global supply chains: A simulation-based analysis on the coronavirus 
outbreak (COVID-19/SARS-CoV-2) case. Transportation Research Part E: Logistics and Transportation Review, 2020. 136: p. 101922.

[16] Lin, Q., et al., A conceptual model for the outbreak of Coronavirus disease 2019 (COVID-19) in Wuhan, China with individual reaction and governmental action. International journal of infectious diseases, 2020.

[17] Beamon, B.M. and B. Balcik, Performance measurement in humanitarian relief chains. International Journal of Public Sector Management, 2008.

[18] Fornaro, L. and M. Wolf, Covid-19 coronavirus and macroeconomic policy. 2020

[19] Maciel Neto, T. and M.B. Gonçalves, Instalações Humanitárias como alternativa de preparação para eventos sazonais no Estado do Amazonas. Journal of Transport Literature, 2015. 9(4): p. 35-39.

[20] Gil, A.C., Como elaborar projetos de pesquisa. Vol. 4. 2002: Atlas São Paulo.

[21] JACOBSEN, A.d.L., Gestão por Resultados, Produtividade e Inovação. Florianópolis, UFSC, 2009.

[22] Mentzer, J.T., et al., Defining supply chain management. Journal of Business logistics, 2001. 22(2): p. 1-25.

[23] Lummus, R.R. and R.J. Vokurka, Defining supply chain management: a historical perspective and practical guidelines. Industria management \& data systems, 1999.

[24] Chen, I.J. and A. Paulraj, Towards a theory of supply chain management: the constructs and measurements. Journal of operations management, 2004. 22(2): p. 119-150.

[25] McKone-Sweet, K.E., P. Hamilton, and S.B. Willis, The ailing healthcare supply chain: a prescription for change. Journal of Supply Chain Management, 2005. 41(1): p. 4-17.

[26] Jahre, M., et al., Improving health in developing countries: reducing complexity of drug supply chains. 2012.

[27] Böhme, T., et al., Methodology challenges associated with benchmarking healthcare supply chains. Production Planning \& Control, 2013. 24(10-11): p. 1002-1014.

[28] Dobrzykowski, D., et al., A structured analysis of operations and supply chain management research in healthcare (1982-2011). International Journal of Production Economics, 2014. 147: p. 514530.

[29] Rivard-Royer, H., S. Landry, and M. Beaulieu, Hybrid stockless: a case study. International Journal of Operations \& Production Management, 2002.

[30] Tortorella, G.L., R. Miorando, and D. Tlapa, Implementation of lean supply chain: an empirical research on the effect of context. The TQM Journal, 2017.

[31] Fillingham, D., Can lean save lives? Leadership in health services, 2007. 20(4): p. 231.

[32] Adebanjo, D., T. Laosirihongthong, and P. Samaranayake, Prioritizing lean supply chain management initiatives in healthcare service operations: a fuzzy AHP approach. Production Planning \& Control, 2016. 27(12): p. 953-966.

[33] Frazzon, E., et al., Simulation-based analysis of a suppliermanufacturer relationship in lean supply chains. International Journal of Lean Six Sigma, 2017.

[34] Sakurada, N. and D.I. Miyake, Application of discrete event simulation in service industry modeling processes. Gestão \& Produção, 2009. 16(1): p. 25-43.

[35] Setijono, D., A.M. Naraghi, and U.P. Ravipati, Decision support system and the adoption of lean in a Swedish emergency ward. International Journal of lean six sigma, 2010.

[36] Jiang, X., X. Qu, and L.B. Davis. Using Data Mining to Analyze Patient Discharge Data for an Urban Hospital. in DMIN. 2010.

[37] Davis, L.B., et al., Inventory planning and coordination in disaster relief efforts. International Journal of Production Economics, 2013. 141(2): p. 561-573.

[38] Ingallis, R. The value of simulation in modeling supply chains. in 1998 Winter Simulation Conference. Proceedings (Cat. No. 98CH36274). 1998. IEEE.

[39] Robinson, S. Conceptual modeling for simulation: issues and research requirements. in Proceedings of the 2006 winter simulation conference. 2006. IEEE.

[40] Jebbor, S., A. El Afia, and R. Chiheb, An approach by human and material resources combination to reduce hospitals crowding. International Journal of Pervasive Computing and Communications, 2019.

[41] Bhakoo, V., P. Singh, and A. Sohal, Collaborative management of inventory in Australian hospital supply chains: practices and issues. Supply Chain Management: An International Journal, 2012. 17(2): p. 217-230.
[42] Moons, K., G. Waeyenbergh, and L. Pintelon, Measuring the logistics performance of internal hospital supply chains-a literature study. Omega, 2019. 82: p. 205-217.

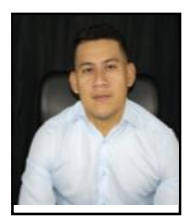

Mayko Pinheiro da Silva is a student in the master's program in Production Engineering at Federal University of Amazonas, he has a degree in accounting and is currently working in the military fire department.

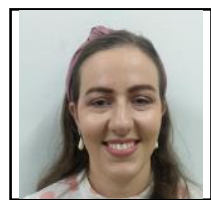

Gabriela de Mattos Veroneze is an Adjunct Professor, in the Department of Production Engineering and member of Master Program in Production Engineering, Federal University of Amazonas. She has published several Research Papers related to Engineering area.

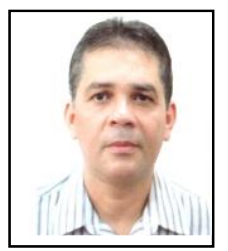

Marcelo Albuquerque de Oliveira is an Adjunct Professor in the Department of Production Engineering and member of Master Program in Production Engineering, Federal University of Amazonas. He has published several Research Papers related to Engineering area.

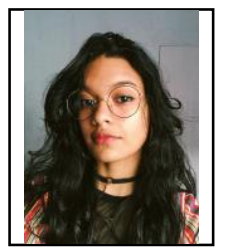

Ingrid Marina Pinto Pereira is an undergraduate research assistant in the Production Engineering department. 